\title{
Assessing Fruit Tree Species Diversity in Home Garden Agro-Forestry and Their Role Supporting Local People's Livelihoods in Burie District, Ethiopia
}

\author{
Alebachew Abebe ${ }^{1, a, *}$, Habtamu Kiros ${ }^{1, b}$, Eba Muluneh Sorecha ${ }^{2, c}$ \\ ${ }^{1}$ Department of Statistics, College of Computing \& Informatics, Haramaya University, P.O.Box 138, Dire Dawa, Ethiopia \\ ${ }^{2}$ School of Natural Resources Management and Environmental Sciences, College of Agriculture and Environmental Sciences, Haramaya \\ University, P.O.Box 138, Dire Dawa, Ethiopia \\ *Corresponding author \\ A R T I C L E I N F O \\ A B S T R A C T \\ Research Article \\ Clearing of natural ecosystems and land degradation due to unsustainable agricultural practices are \\ becoming threats to the sustainability and productivity of agricultural systems in Burie town \\ administrative, Amhara National Regional State, Ethiopia. The aim of this paper is therefore to \\ assess the fruit tree species diversity in home garden agro-forestry and their role for supporting local \\ Received : 17/04/2018 \\ Accepted : 08/04/2019 \\ people's livelihoods in Burie town administration. Cultivated plants of 72 home gardens were \\ surveyed and critical information were collected through questioner and focus group discussion from \\ 12 households. Fruit tree species diversity (expressed in species richness and evenness) in home \\ gardens in the study sites was determined using the Shannon-Weiner Index. The study basically \\ considers the human consumption fruit trees species. A total of 18 fruit tree species represented by \\ Keywords: \\ Home garden \\ 9-genera and 7-families were recorded in home garden agro-forestry within the three wealth status \\ (poor, medium, and rich) of the selected respondents commonly. From all wealth categories, the \\ highest Shannon diversity index was recorded in rich and the lowest was in poor class category. \\ Species diversity \\ Species richness \\ Shannon-Diversity Index \\ Similarly, the highest species evenness was recorded in rich wealth category. However, there was \\ no significant difference among rich and medium wealth categories for species richness. The study \\ also revealed that age, land hold size, education status is the cause for species diversity in addition \\ to the wealth status in the study area. Older respondents had significantly higher species richness \\ and diversity than youngsters. It has been also found that almost all $(100 \%)$ of the sampled \\ households harvest and use at least four types of home garden products for various purposes. Lacks \\ of management practices were the factors which puts the species diversity in question in the study \\ area.
}

\section{Introduction}

Agriculture is dominated by smallholders whose farming is considered as the basis for the national economic development. Due to the increment of land fragmentation and environmental and societal change, many Ethiopian smallholders are in the process of transforming their farming policy to meet their needs for household food security and income. Currently, many of the farmers in Ethiopia are changing their farming practice to mixed farming (Djurfeldt et al., 2011).

Home garden is commonly defined as land use systems involving deliberate management of multipurpose trees and shrubs in intimate association with annual and perennial agricultural crops and invariably, livestock within the compounds of individual houses, the whole treecrop-animal unit being intensively managed by family labor (Kumar and Nair, 2006).
Home-gardens provide both economic and social advantages. With their various agricultural crops and trees, accomplish the basic needs of the local population. In addition, home gardens provide economic, social and cultural benefits while remaining ecologically sound and biologically sustainable (MoFED , 2007).

Home-garden agro forestry practice is complex, diversified and highly traditional part of plant biodiversity conservation and utilization. High plant diversity in the home gardens, a wide spectrum of multiple-use plant products can be generated with relatively low labor, cash or other inputs. In seasons of food scarcity home gardens with their diverse products available year round, contribute towards food security (Kehlenbeck and Maass, 2004).

Fruit production is an integral part of home garden to ensure quality food, dietary diversity and nutrition, 
particularly for vulnerable groups such as children, women and the elderly. Tropical fruit tree species diversities are rich on homesteads and farms of fruit tree growers' households and have a number of economic, social, cultural, aesthetic and ecological functions important to livelihoods (Tesfaye et al., 2010). From the conservation standpoint, home gardens can serve as buffer zones around protected forests or community forests. For instance, a study in Meghalaya, India, showed that deforestation was eroding Citrus wild diversity while a number of the species were maintained in home gardens (Shannon and Wiener, 1949).

The selection of plant species for their arrangement and management varies within and between home gardens in the same community Mendez et al. (2001) which can be influenced by many ecological, social and economic factors (Wezel and Bender, 2003).

However, the decision making processes and patterns of the farmers who practice fruit tree in homestead agro forestry is important in expanding and improving the practice Salam et al. (2000) and also for including Home garden as a strategic component of in situate conservation of agro-biodiversity. Kumar and Nair (2006) argued that the main determinants of the biotic change and variation, literature sources account it for ecological, personal, sociocultural and economic as well as political factors.

Thus, fruits have significant importance with a potential for domestic and export markets, and industrial processing in Ethiopia (Withrow-robinson and Hibbs, 2005). The main fruits produced and exported include Banana (Musaedible cultivars), Citrus fruits, Mango (Mangifera indica) and Avocado (Persea americana), Papaya (Carioca papaya) and Grape fruits (Citrus paradisi). Many parts of the country are suitable for growing temperate, sub-tropical or tropical fruits. In the southern and south-western parts of the country due to favorable climate, abundant labor, land and water resources, sufficient rainfall to support fruits adapted to the respective climatic conditions production of fruits are high. Around 47000 hectares of land with a production capacity of 3.5 million quintals is under fruit production in Ethiopia. Of which, Banana covers about $61 \%$, and followed by mango (13\%) (CSA, 2008). Of the total of fruits produced in Ethiopia, only less than $2 \%$ is exported (Joosten, 2007).

With the hope of contributing to the expansion of fruit based agro-forestry, has documented fruit tree resources from home gardens with assessment to species diversity, management practices, contribution to rural small holder livelihood security, as well as the underlying constraints and enabling factors, in the study area. Home gardens in Burie district are also considered as sustainable systems of agro-forestry. However, home gardens in the Burie district especially in WanGedam and Baguna kebesa villages have not been evaluated in depth for their species composition. Thus, quantifying the species diversity of fruit plant by determining their species composition in selected villages of the district and to examine the agro-economic characteristics of the species with their economic contribution to the livelihood of the local people is to be investigated. This will possibly fill the information gap on fruit tree species of the area through assessing fruit tree species diversity in home garden agro-forestry and their contribution to the livelihood.
Despite the wide area coverage production of fruit tree and multiple benefits of fruit trees in the home garden agroforestry system of fruit tree grower farmers of the study area, the contribution of fruit trees for supporting local people's livelihoods and their diversity in home garden Agro-forestry system of the study area is not yet studied. The objective of this study was to assess fruit tree species diversity in home garden agro-forestry and their role for supporting local people's livelihoods in Burie district, West Gojjam Zone, Ethiopia.

\section{Materials and Methods}

\section{Description of the Study Area}

Burie district is located in the Amhara National Regional States (ANRS) lying within 10.42N and 37.04E. The district is found $400 \mathrm{~km}$ North West direction from Addis Ababa capital city of the Ethiopia. Burie is one of the fifteen districts of west Gojjam Administration zones of ANRS (Figure 1). The total population size of the district is 143,099 of which 71,189 male and 71,910 female peoples, of this 25,971 live in urban and 117,128 lives in rural (CSA). Totally 721 households are living in the WanGedam kebele and Bagunakebesa (Table 1). Also in the kebele 367 and 354 household are living respectively according to the Burie Town Administrative Agriculture Office. Among those some villages has irrigation on the Selala and Denesera River (informal talk with Burie District Agricultural and Development Office).

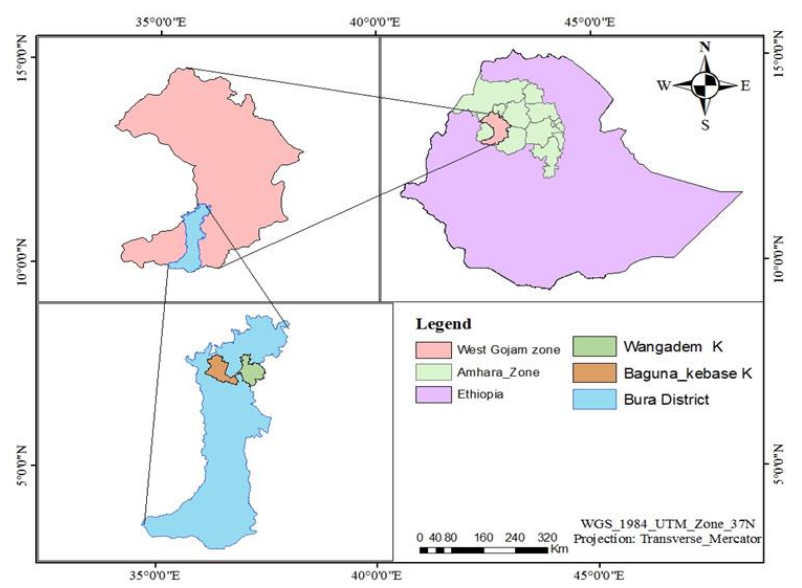

Figure 1 Map of the study area

The livelihood of the local community in Burie Town Administrative is mainly based on mixed farming system crop production and livestock rearing while some are participating in off farm activities. Farmers in the area grow cereal crops such as Eragostic steff, Zea mays, Pisum sativum.

In addition, Guizoia abyssinica is growing; but these are limited in their coverage. On the other hand, along the rivers which is found in the area like, Selala and Densera River small scale irrigation practices are taking place and most of the time horticultural crops and fruits are producing. Livestock production is also another major agricultural activity of the area. The common types of animals reared in the study area are cattle, donkey etc. In addition to this poultry production and beekeeping also practice in some areas. 
Table 1 Number of households in each the selected villages

\begin{tabular}{|c|c|c|c|c|c|c|c|c|c|c|c|}
\hline \multirow{3}{*}{ No } & \multirow{3}{*}{ Village } & \multirow{3}{*}{ No of $\mathrm{HH}$} & \multicolumn{9}{|c|}{ Sample size } \\
\hline & & & \multicolumn{3}{|c|}{ Respondents $10 \%$} & \multicolumn{2}{|c|}{ Rich } & \multicolumn{2}{|c|}{ Medium } & \multicolumn{2}{|c|}{ Poor } \\
\hline & & & Male & Female & Total & Male & Female & Male & Female & Male & Female \\
\hline 1 & Wangedam & 367 & 31 & 6 & 37 & 9 & 1 & 12 & 2 & 10 & 3 \\
\hline 2 & Baguna kebesa & 354 & 30 & 5 & 35 & 9 & 1 & 16 & 2 & 5 & 2 \\
\hline 3 & Total & 721 & 61 & 11 & 72 & 18 & 2 & 28 & 4 & 15 & 5 \\
\hline
\end{tabular}

The climatic condition of the Burie District is divided in to $90 \%$ Woina-Dega (warm to cool semi-arid) and $10 \%$ Dega (cool to cool humid) agro climatic zones. The area has unimodal rainfall with a rainy season that goes from June to September where the mean annual rainfall varies from $1200 \mathrm{~mm}$ to $1500 \mathrm{~mm}$, the minimum and maximum temperature of the area is 17 and $250^{\circ} \mathrm{C}$, respectively. During the dry seasons, irrigation agriculture is common and practiced in some villages of the district (Burie Agricultural Development Office). The altitude of Burie District ranges from 700-2300 m above mean sea level and topography of the study area is found to be plain. Burie District has 10\% Dega and 90\% is Woina-Dega according to Burie District Agriculture Office.

The common of vegetation type found in the study area is indigenous species of trees like Croton macrostachyus, Cordia africana, Ficusvaste, Juniperus procera and exotic species of trees like Eucalyptus globulus are the major types of trees in the Burie District of which Cordia africana and Croton macrostachyus are the dominant species of tree from indigenous species while Eucalyptus globulus is dominant from foreign species of trees. But as a result of human interference, mainly conversion of the forest land of farmlands, clearing and cutting trees for fuel wood, charcoal and settlement purpose, the vegetation cover of the area is extremely decreased.

\section{Study Site Selection}

At the beginning, preliminary survey was done that include transect walk, formal and informal conversation with stockholders, in order to identify two representatives village. These villages were selected purposefully based on the availability of fruit tree in home garden agro-forestry practice. From the selected village; six small villages were select purposively and also from each village we selected $10 \%$ of the total household.

\section{Household Sampling Techniques}

Stratified sampling method was employed to select the respondents. Stratification was based on wealth classes (Poor, Medium and Rich) with the help of people who lived long in each village. The wealth class stratification was used to get representative sample from all wealth groups in order to assess the variations in the use of fruit tree in Home Garden (HG) by households. The samplings of households $(\mathrm{HH})$ from the total population of the selected village were determined the sample size. From the total households of selected village, households were selected purposefully.

\section{Data Collection and Data Analysis}

Primary data collection was conducted through quantitative techniques. For the quantitative technique it was implemented the survey method to enable to capture the characteristics and attributes of the respondents through a questionnaire. In addition to the interviews, focus group discussions (FGDs), field observation, informal conversations and transect walk was also employed. These different data collection methods were used with the objective that the method was complement each other in order to get rich and insightful information.

Secondary data was collected from published and unpublished sources. Burie Town Administrative Agricultural Offices, Cooperative Promotion Offices, West Gojjam Zone of Natural Resource Office, Amhara Natural Resource Bureau will the key source. The socio-economic data collection was carried out by using the following methods. All data for this study was collected through key informants selection, household interview, focus group discussion, inventory of home garden, and direct observation.

The data was subjected to statistical analysis. The data generated from semi-structured surveys was triangulated to enhance the accuracy and categorization was made for analysis. The statistical analysis was conducted using statistical software of SPSS Version 25.0, SAS Version 9.2 and the results presented in a summarized form using descriptive statistics such as means, percentages, tables and graphs. Chi-square test was also be done for if there is any association between the wealth categories and the participation, age and the attitude toward fruit tree in home garden agro forestry practice. Other data collected, summarized and presented. And finally it was appropriately interpreted. Sex, age, wealth, education, and occupation of the respondents were used as independent variables and the dependent variables are management practice and participation. Data obtained from the group discussion was also analyzed descriptively. In general, multiple comparison test and simple descriptive statistic will be applied for analysis.

\section{Analysis of Species Diversity}

Fruit tree species diversity in home gardens in the study sites were determined using the Shannon-Weiner Index $\left(H^{\prime}\right)$ through the analysis of species richness (the number of species in the sample) and evenness of species (abundance distribution among species). The data on diversity were processed and analyzed. Fruit tree species diversity in sites was subjected to one-way ANOVA.

In species diversity study, two components were employed: richness and evenness. The species richness refers to the number of species per plot while evenness refers to their distribution within and between the different populations. To determine species richness of each garden, species index $(\mathrm{S})$, which is simply the total number of species on a plot were calculated. However, this index does not indicate the relative proportion or abundance of a 
particular species on the plot. Shannon diversity index, $\mathrm{H}^{\prime}$ Shannon and Wiener (1949) and evenness measures (E) which are commonly used tools for these purposes Magurran (2004) was calculated.

The Shannon-diversity Index H' can be calculated, to analyze the diversity of species per plot and the formula as follows:

$$
H^{\prime}=-\sum_{i=1}^{S}\left(p_{i} \ln p_{i}\right)
$$

Where $H^{\prime}=$ Shannon-Wiener Diversity Index, $\mathrm{s}=$ number of species $\mathrm{P}_{\mathrm{i}}=$ the proportion of individuals or abundance of the $i^{\text {th }}$ species expressed as Proportion of the total abundance

$\ln =$ natural logarithm of $\mathrm{P}_{\mathrm{i}}$

Values of the Shannon diversity index $\left(\mathrm{H}^{\prime}\right)$ usually lies between 1.5 and 3.5 , although in exceptional cases, the value can exceed 4.5 .

Evenness (Equitability) index: Evenness (Shannon equitability) index (E) was calculated to estimate the homogeneous distribution of fruit tree species on home garden.

$$
\mathrm{E}=\frac{\mathrm{H}^{\prime}}{\mathrm{H}_{\max }}=\frac{\mathrm{H}^{\prime}}{\ln \mathrm{s}}=\text { with } \mathrm{H}_{\max }=\log \mathrm{N} \frac{\sum_{\mathrm{i}=1}^{\mathrm{s}} \mathrm{p}_{\mathrm{i}} \ln \mathrm{p}_{\mathrm{i}}}{\ln \mathrm{s}}
$$

$$
\begin{aligned}
& \text { Where; } \\
& \mathrm{E} \quad=\text { Evenness } \\
& \mathrm{H}^{\prime}=\text { Shannon-Wiener Diversity Index } \\
& \mathrm{H}_{\max }=\ln \mathrm{S} \\
& \mathrm{S} \quad=\text { total number of species in the sample }
\end{aligned}
$$

\section{Results and Discussion}

Demographic Characteristics of the Respondents

Sex and occupation: According to the respondents, 84.7\% male headed (in Amharic Abawera) and 15.3\% were female headed (in Amharic Emawera). In the study area, all of inhabitants are Ethiopian Orthodox and Amharic speakers. Agriculture was the principal occupation for all of the households (Table 2).

Age and education: According to the result, $68.4 \%$, $15.8 \%$ and $15.8 \%$ were found in all wealth status (rich, medium and poor households) and categorized under the age $20-39 ; 17.6 \%, 73.5 \%$ and $8.8 \%$ were also found under the age of $40-59$ and $5.3 \%, 21.1 \%, 73.7 \%$ are found in greater than or equal to 60 years old. Statistically there is significant difference between wealth status among age class. This shows that majority of poor respondents were older. These may be is attributed that the wealth uses more man power than the more aged households (Table 3).

From the result medium and rich $15 \%$ and $85 \%$ were literate (only can read and write), respectively. Moreover chi-square test indicated that, there is a visible difference between wealth status with regard to education level. This implies that, rich farmers are managing their agriculture activities in a better way. In his analysis on socio-economic context and development strategy for tree growing Raintree (1991) pointed out that factors that are relevant to consider under the broad heading of socio-economic will vary from place to place. Among the most important are:degree of local socio-economic stratification (by wealth, land holding size, gender, ethnic group etc.); access to resources (land and tenure); overall economic development strategy; general approach to tree planting programmers, opportunity for relocation of resources; access to credit; processing technology and marketing assistance etc.

Land holding size: One-way ANOVA showed that there is significant differences $(\mathrm{P}=0.000)$ in the crop land holding across the three wealth categories. Land holding size of rich $\mathrm{HH}$ was 2 ha minimum and 3 ha maximum, in medium $\mathrm{HH} 2$ ha maximum and 1 ha minimum was recorded. Whereas, the poor one has a maximum and minimum land size of was 1 ha and 0.5 ha, respectively (Table 4). Because of this land is the major of wealth classification criteria in the study area. In the case of home garden size under the wealth status, the rich $\mathrm{HH}$ respondent has a minimum of 0.125 ha and maximum of 1 ha. The poor $\mathrm{HH}$ has a minimum of 0.03 ha and maximum of 0.12 ha of home garden size. It showed a declining trend from the rich to the poor wealth class because of the rich $\mathrm{HH}$ has large landholding than poor $\mathrm{HH}$. The sizes of home garden differ significantly between the wealth classes $(\mathrm{P}<0.05)$.

The average home garden land holding in the poor households is fairly comparable to what has been reported for tropical home gardens, 0.50 ha Fernandes (2003) and Ethiopian gardens, $40-50 \mathrm{~m}^{2}$ as well as other countries (Wezel and Bender, 2003) but rich and medium have much greater than this (opposite) as seen from Table 4.

Table 2 Demographic characteristics of the respondents $(n=72)$ at the study PAs

\begin{tabular}{ll|cc}
\hline \multicolumn{2}{c|}{ Demographic Characteristic } & Number & Percent $(\%)$ \\
\hline \multirow{2}{*}{ Sex } & Male Headed & 61 & 84.7 \\
& Female Headed & 11 & 15.3 \\
\hline Occupation & Agriculture & 72 & 100 \\
\hline
\end{tabular}

Table 3 Socioeconomic characteristics of the respondents among wealth classes $(n=72)$

\begin{tabular}{ll|ccc}
\hline \multirow{2}{*}{ Variable } & \multicolumn{3}{c}{ Wealth status } \\
\cline { 3 - 4 } Age & $20-39$ & Poor $(\%)$ & Medium $(\%)$ & Rich (\%) \\
\hline \multirow{3}{*}{ Education } & $40-59$ & 15.8 & 15.8 & 68.4 \\
& 60 and above & 8.8 & 73.5 & 17.6 \\
& Can read and write & 3.3 & 21.1 & 73.7 \\
& Not read and write & 66.3 & 75 & 87.5 \\
\hline
\end{tabular}


Table 4 Land size by wealth status of the respondents

\begin{tabular}{|c|c|c|c|c|c|c|c|c|c|}
\hline \multirow{3}{*}{ Variable } & \multicolumn{9}{|c|}{ Wealth status } \\
\hline & \multicolumn{3}{|c|}{ Rich } & \multicolumn{3}{|c|}{ Medium } & \multicolumn{3}{|c|}{ Poor } \\
\hline & Mean \pm sd & Min. & Max. & Mean \pm sd & Min. & Max. & Mean \pm sd & Min. & Max. \\
\hline Crop land & $2.62 \pm 0.23$ & 2 & 3 & $1.77 \pm 0.27$ & 1 & 2 & $0.8 \pm 0.19$ & 0.5 & 1 \\
\hline HG size & $0.43 \pm 0.35$ & 0.125 & 1 & $0.188 \pm 0.24$ & 0.03 & 0.75 & $0.06 \pm 0.03$ & 0.03 & 0.12 \\
\hline
\end{tabular}

Min=minimum, Max=maximum, $\mathrm{sd}=$ standard deviation

Generally, households have different size of home garden; similar report was reported by Fentahun (2008) in Western Amhara Region, and also according to Tsegazeabe et al (2012), in the Hintalo Wejerat district, people maintain home garden in different size. The average size of the home gardens were reported to be ranging from about $500 \mathrm{~m}^{2}$ to more than $2.500 \mathrm{~m}^{2}$ (a quarter of a hectare), but in extreme cases, home gardens as small as $20 \mathrm{~m}^{2}$ and as large as $10.000 \mathrm{~m}^{2}$ have been reported in this area.

In the rich, medium and poor $\mathrm{HH}$ Mean \pm sd of land holding size were $2.62 \pm 0.23,0.188 \pm 0.24$ and $0.06 \pm 0.03$, respectively (Table 4). There was significant differences in the crop land holding across the three wealth categories (one-way ANOVA, $\mathrm{P}<0.05$ ). Home garden size was directly proportional to crop land size which is in contrary to what has been reported by Fentahun (2008) in Western Amhara Region, it is households with small farm sizes allocate a significantly larger land for gardening. According to Tsegazeabe et al. (2012), larger home gardens are most frequent in households where the home garden is the only cultivated land available to stallholder farmers.

\section{Floristic Composition and Diversity of Fruit Tree}

Floristic composition of fruit tree: Although larger number of species is grown in home gardens relative to the fields, home gardening is not adequately practiced in the study area round. Part of the reason for this may be related to the shortage of water sources in the area. However, the results indicate that local people work hard to harmonize their environment by planting many species of plants with various uses. This is usually practiced in their home gardens. Hence, the home gardens are similar to other traditional home gardens in the country mentioned by Wojtkowski (1993) house diverse species of plants. Very rare plant species of the area were encountered in these poorly developed gardens. This corroborates with earlier results which reported that home gardens serve as refuges for endangered useful species. Similar to most parts of the country (e.g., (Wojtkowski,19 93) the home gardens in the study sites are located in close association with living houses, composed mainly of food plants.

This study focused on fruit tree species composition, when crop composition considered, the home gardens are typically of the mixed type. From the study, a total of 18 fruit tree species that are represented by 9 genera and 7 families were recorded in home garden agro-forestry at the three wealth status of the selected respondents. The highest number of fruit tree species (18) was recorded at rich and medium household, while (9) fruit tree species were recorded at poor household. The highest number of (13) genera and (10) families were observed in rich and medium household; where as in the poor household (9) genera and (8) families were observed. Generally, Citrus and Rutaceae emerged the most dominant genera and family of fruit tree species in the three wealth class of the respondents. Among the families at rich and medium household Rutaceae was the most diverse family represented by 7 fruit tree species and the highest composition of site followed by Myrtaceae and Moraceae represents 2 species for each family then Caricaceae, Antacadiaceae, Lauraceae, Musacease, Rosaceae, Boraginacea each represented by 1 fruit tree species composition.

At poor household, like in the rich and medium household the most diverse family of fruit tree species was Rutaceae represented by 5 species composition of the site followed by Myrtaceae, Moraceae, Caricaceae, Antacadiaceae, Lauraceae, Musacease, which was represented by one species. But according to Tsegazeabe et al. (2012), a total of over 40 plant species were recorded in home garden in Hintalo Wejerat district into the categories of vegetables, fruit trees and fodder trees. Home garden plant composition was found to be dominated by vegetables followed by fruit tree; from the total 17 were fruit tree species. This result was similar across the two study sites. Fruit tree species composition on the three wealth class of the respondents $(n=72)$ at the study site.

Frequency of fruit tree species: The frequency occurrence of each species across wealth status of the study site is presented in (Figures 2). Distribution of the species along the wealth status of the respondent showed the existence of variation from wealth status of all study respondents. At the rich household, Musa acuminate (100\%), Mangifera indica (100\%) and Percea american $(100 \%)$ were the most frequently recorded fruit tree species in all of the study respondents followed by Musaca acuminata (93.75\%), Citrus aurantifolia (80\%), Prunus persia (90\%) and Citrus aurantim (41.18\%). However, other three fruit tree species (Casimiroa edulis, and Psidium guajava) were the same $29.4 \%$ of frequent species. The other frequent fruit tree species were papaya and Citrus medica each encounter in $23.53 \%$ and $5.88 \%$, respectively.

Of the total fruit tree species recorded at the poor household respondents, Magnifera indica (100\%) were the most frequently recorded fruit tree species in the respondent followed by Musa acuminata and Percia american (91.67\%). Other fruit tree species recorded in the poor household are the least frequently recorded fruit tree species. Generally, Musa acuminata (100\%), Mangifera indica $(100 \%)$ and Percea american (100\%) were the most frequently recorded fruit tree species of the study respondents.

Fruit tree species diversity: In order to get better picture on extent of fruit tree species diversity, several diversity indices were employed which include Shannon, Evenness and Simpson diversity indices. Woody species diversity was significantly higher in rich than medium and poor wealth categories. Similarly, the tree diversity indices were significantly higher for the medium wealth category than the poor. From all wealth categories, the highest Shannon 
diversity index was recorded in rich and the lowest in poor class. Similar to Shannon value, highest species evenness was recorded in rich wealth category. However, there was no significant difference $(\mathrm{P}>0.05)$ among rich and medium wealth categories for richness of species (Table 5).

According to Tefera et al. (2015), in Sebeta-Awas it was found that food plants (fruits, vegetables, legumes and pulses) constituted $25 \%$, of the recorded home garden species where the most frequently maintained crops in the home gardens of Sebeta Town were reported to be those that serve as source of food.

Management of Fruit Tree in Home Garden AgroForestry Practices

Home gardens in the study area receive different management attentions by household members (Table 6) Activities like planting material production, weeding, hoeing, manuring, watering, harvesting, pruning and coppicing are taking place in garden management. As shown in (Table 6), the majority $(84.5 \%)$ of home gardens receives a combination of cultural practices like hoeing, weeding, manuring and harvesting. About $48 \%$ of planting materials are both the combination of self-establishment and brought from neighbor farmers in the study sites. Moreover, highest percentage of planting materials in the study site was Go nursery sit. Weeding and hoeing was done by hand by using sickle, hoes, spades or forks in order to reduce resource competition for crop and to facilitate water infiltration in study sites. Livestock are integral part of the home garden agro forestry land use in the study area. Livestock provides manure for maintaining soil fertility maintenance. The home gardens are low-input agricultural systems which receives little or no external in puts like chemical fertilizer. Accordingly, soil fertility maintenance in the studied home gardens predominantly employs the application of manure, household waste, compost, and ash.
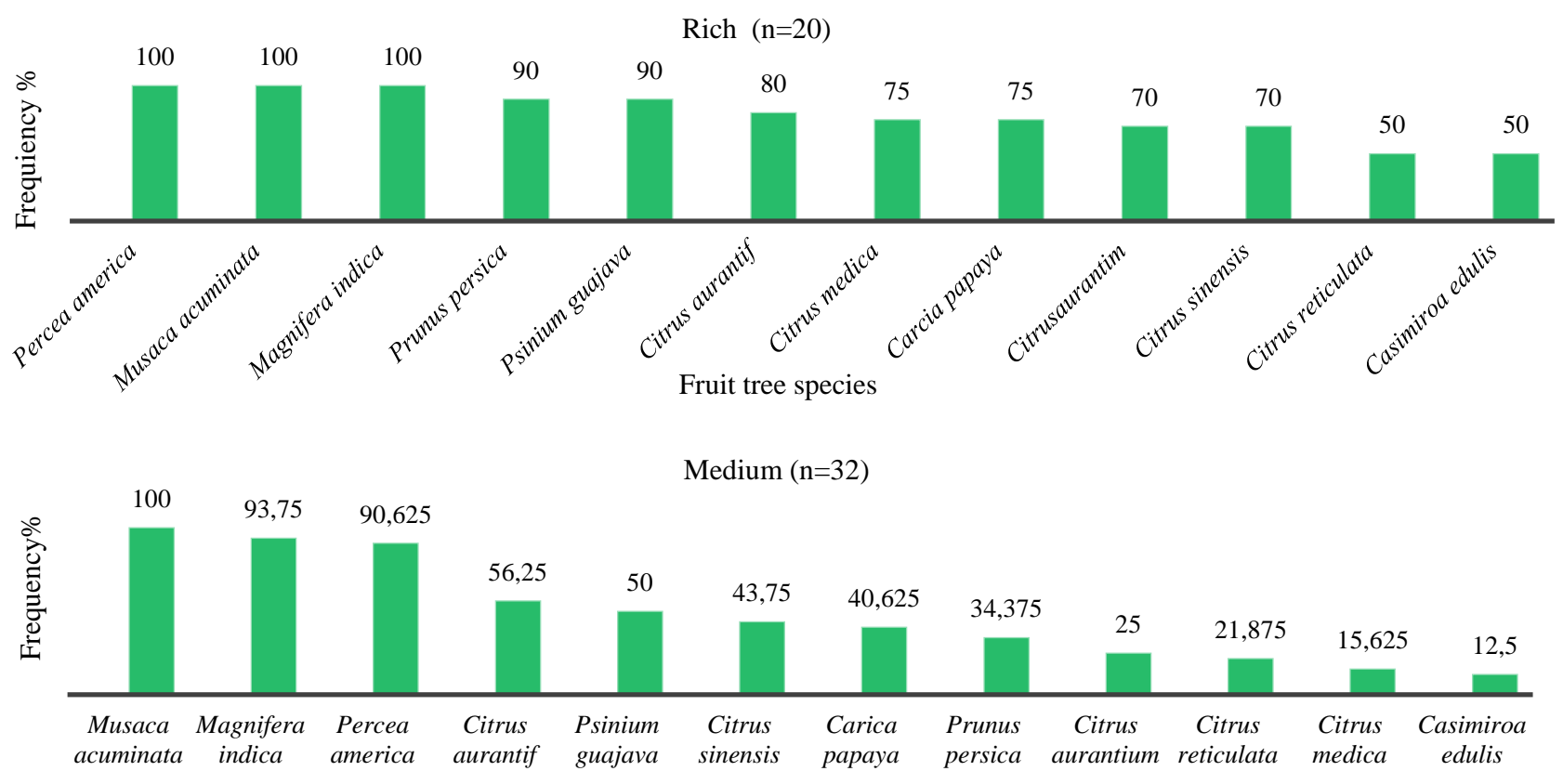

Fruit tree species

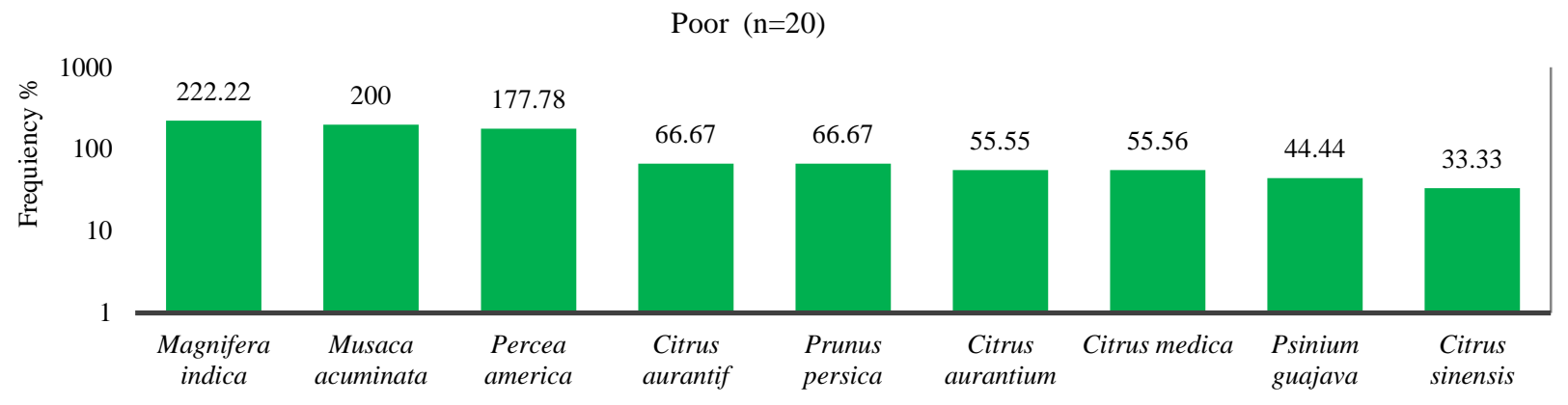

Fruit tree species

Figure 2 Frequency occurrences of fruit tree species in wealth status of study site

Table 5 Mean $( \pm \mathrm{SD})$ Richness, Shannon and Evenness diversity index of three wealth categories at the study site.

\begin{tabular}{l|ccc}
\multicolumn{1}{c|}{ Wealth categories } & Richness & Shannon & Evenness \\
\hline Poor & $8 \pm 1.34^{\mathrm{a}}$ & $1.84 \pm 0.14^{\mathrm{a}}$ & $0.83 \pm 0.06$ \\
Medium & $11 \pm 1.36^{\mathrm{b}}$ & $1.95 \pm 0.08^{\mathrm{b}}$ & $0.78 \pm 0.03$ \\
Rich & $11 \pm 0.57^{\mathrm{b}}$ & $2.29 \pm 0.07^{\mathrm{c}}$ & $0.92 \pm 0.03$ \\
\hline
\end{tabular}

Small letter indicates differences $(\mathrm{P}<0.05)$ among each wealth classes within study site 
Table 6 Management practices of plants

\begin{tabular}{l|ccccccc}
\hline \multirow{2}{*}{\multicolumn{1}{c|}{ Management Practices }} & \multicolumn{6}{c}{ Wealth Categories } \\
\cline { 2 - 8 } & \multicolumn{2}{|c}{ Poor (\%) } & \multicolumn{2}{c}{ Medium (\%) } & \multicolumn{2}{c}{ Rich (\%) } \\
\cline { 2 - 8 } & Yes & No & Yes & No & Yes & No \\
\hline Compost & 58.3 & 41.7 & 91.2 & 8.8 & 100 & 0 \\
Pruning & 0 & 100 & 24.6 & 75.4 & 82.4 & 17.6 \\
Thinning & 0 & 100 & 12.3 & 87.7 & 47.1 & 52.9 \\
Grafting & 0 & 100 & 7 & 93 & 29.4 & 64.7 \\
\hline
\end{tabular}

Table 7 Source of seedlings

\begin{tabular}{l|ccc}
\hline \multirow{2}{*}{ Source of Seedling } & \multicolumn{3}{c}{ Wealth Category } \\
\cline { 2 - 4 } & Poor $(\%)$ & Medium $(\%)$ & Rich (\%) \\
\hline Self-establishment & 8.33 & 15.54 & 16.53 \\
From neighbor farmer & 55.63 & 17.54 & 3.88 \\
From wild & 2.7 & 5.51 & 8.7 \\
Government nursery site & 33.33 & 61.4 & 70.89 \\
\hline
\end{tabular}

Manure is the major source of soil nutrient more than half of the home gardens use a combination of manure house hold waste and compost. Another management activity is pruning of multipurpose trees (MPTs) in home gardens in the study sites. Owing to this practice, different tree species are cultivated mixed with annual and perennials in the home gardens. The practice of pruning of indigenous trees in home gardens is done for various purposes. It improves light interception by the herbaceous layer beneath the trees and pruned twigs are also used as fodder.

Management practice of the study site among wealth category is, $100 \%, 91.2 \%$ and $58.3 \%$ of rich, medium and poor use compost respectively. The other management practice lick pruning, thinning and grafting doesn't used by poor according to the result of data; in contrast to poor, medium and rich household use pruning 24.6 and $82.4 \%$, respectively. Farmers in the study site employed various management practices which help them for the better utilization of home garden plant species. Out of them the most common management activities are hoeing, weeding, planting, fertilizing, harvesting and pruning in the study sites. Hoeing was generally done by hand, using very simple tools like hoes, spades or forks to facilitate water infiltration and air circulation in the soil across the study sites. It also used to reduce weed competition. Weeding was done by hand in order to reduce resource competition for crop in the study sites. The pruning of indigenous species branches in home gardens for reducing the effect on crops, getting fodder for animals, and collecting wood to be used for fencing, constructing houses, and firewood. This is in line with the result of (Tefera et al., 2015; Shannon and Wiener, 1949) who reported in most part of the rural people uses different management practices.

The result of this study revealed that home gardens in study sites received different management attentions by household members. Soil fertility in home garden was maintained mainly by using animal manure, household wastes and crop residue. The finding of the study is in line with the result of Fentahun (2008) who reported that the major source of soil fertility in home garden is animal manure, kitchen and house wastes, and ash. Livestock's are integral part of the home garden agro forestry land use and they provided manure for maintaining soil fertility maintenance in the study sites.
This finding is also comparable with the earlier studies conducted elsewhere. Example, Tanzania home gardens Kumar and Nair (2006), Kerala, India home gardens arrived at the same conclusion. Similarly, Withrowrobinson and Hibbs (2005) reported livestock are source of soil fertility management in home gardens. In the study site farmer's do not used industrial fertilizer such as UREA for fruit tree seedling. In contrast to this finding, some authors reported that home gardeners used industrial fertilizer in the Napu valley home gardens (Mendez, 2000).

There are different source of planting material in the study sites (Table 7). Own gardens or self-established planting material are main sources for different plant species in the study site. Large parts of staple crop species (vegetables, fruit, and root and tuber crops) planting materials are already planted by garden owners in this site. The finding of the study is comparable to earlier studies elsewhere. For instance, Sunwar (2003) reported the majority of sources for planting materials for home gardens are self-saved/established by farmers themselves. Farmers brought large portions of the planting materials from their neighbor farmers (i.e. sharing between home gardens owners) in the study site. This finding of the study is similar with the result of Sunwar (2003) reported sharing among farmers are contributed relatively large amount of planting materials in Western Nepal home gardens. Few fruit, coffee and seedling received from wild and buy from the market in the study sites. Similarily, Sunwar (2003); Fentahun (2008) reported farmers obtained home garden species from market or outside the local community and GOs nursery site. However, still access of infrastructure such as road facilities is major problem to exchange and share planting materials among them in the study sites.

According to wealth categories, the result of the study shows that rich people will receive about $70.89 \%$ seedling from the government nursery site. But, poor people attained much amount of seedlings from their neighbors, accounting $55.63 \%$. Plant seedling by self-establishment is relatively small in the poor status people than rich (Table 7).

Farmers of the study site have different sources of germplasm. According to the current study, selfregeneration, own nursery and others (sharing between home gardens owners) were the main sources. The finding of the study is comparable to earlier studies done elsewhere. For instance, Tefera et al. (2015) reported the majority of sources for planting materials for home gardens are self-saved/established by farmers themselves. Most 
fruit, seedling received from government nurseries in the study sites. Similarly, Tefera et al. (2015); Fentahun (2008) reported farmers obtained home garden species from government organization nursery site.

\section{Contribution of Home Garden to Household}

Home garden of the study sites are an assemblage of annual and perennial crops, which are major source of food for the household both in time of food shortage periods and in providing dietary requirements. In the study site, farmers are growing different species in their home garden primarily for household consumption and to lesser extent income generation.

The diversity of functional groups in the home gardens is a clear indication of the diversity of services (food, fodder, wood, medicine, income generation etc.) these home gardens provide for the household. In addition to providing food source, these gardens are source of medicinal plants and fuel wood and construction material. Fruit trees do not only supplement the dietary requirement of the household but are also sources of income. In the same line, coffee and chat (stimulants) are major sources of income while satisfying household consumption. A similar diversity of home garden plants has been reported across Ethiopian gardens (Wojtkowski, 1993).

Farmers of the study site manage home garden for various purposes. It plays a vital role in contributing to livelihood of respondent households. During discussion, respondents categorized products of home gardens fruit tree in to, namely food crops, cash crops, animal feed, fuel wood, timber, handles and household utensils, medicinal plants, spices, farm implements and honey. Almost all of the sampled households harvest and use at least four types of home garden products among those listed above.

\section{Food and Cash Crops}

Farmers grow various food and cash crops in their home garden. Coffee arabica, Persia americana, Mangifer aindica, Musa paradisiacl, Casimiroa edulis, cordia africana, Ficus spps etc, managed in their home garden. Fruit tree species plays a vital role in providing food for household consumption in the study site both during rainy and dry seasons. Almost all (100\%) surveyed household's use fruit for food and cash income. Coffee product harvested from the home garden serve for household consumption and cash income generation. The most common home garden products that the households sold were timber, honey and fruits. The rest of home garden products were mostly collected for household consumption (FGD).

\section{Fuel Wood}

Fuel wood is the main source of energy to all (100\%) of the respondents. Farmers harvest fire wood from homegarden to prepare any household food. Cordia africana, Albizia gummifera, ficus species, Grevillea robusta and other shrubs species are the main sources of fuel wood in home garden. According to this study, almost all households harvested on tree species for preparing food in the form of charcoal or as it is the dry tree for fire.

\section{Household Utensils and Honey}

The other common materials that the farmers utilize from the home garden are wood for handles of various tools and making household utensils. The most common tool handles identified by respondents for which wood is harvested from Cordia africana that produce timber for furniture and household utensils like, axe, shovel, table, chairs, bed, door, window etc.

Trees play an important role for bee management. They serve for hanging beehives and providing fodder. Discussion with farmers showed that honey production is an age old practice and still remains an important practice. During survey, it was observed that hives were placed around home, on trees grown in home garden and crop lands (Figure 3). Trees commonly used for hanging beehives include Cordiaafrican, Croton macro stachyus, Magnifer aindica and Ficus spp. Farmers hang beehives on the trees and harvesting of honey done once or twice a year, i.e., in May or November. The most preferred trees for beeforage in home garden are Cordia africana, Croton macrostachyus and Vernonia amygdalina. Information obtained from this study indicated that farmers used honey production as means of cash and medicinal purpose. Most of the study site bee keeper households use traditional beehive-based honey production system and few of them use modern beehives in addition to tradition hives (Figure 4).

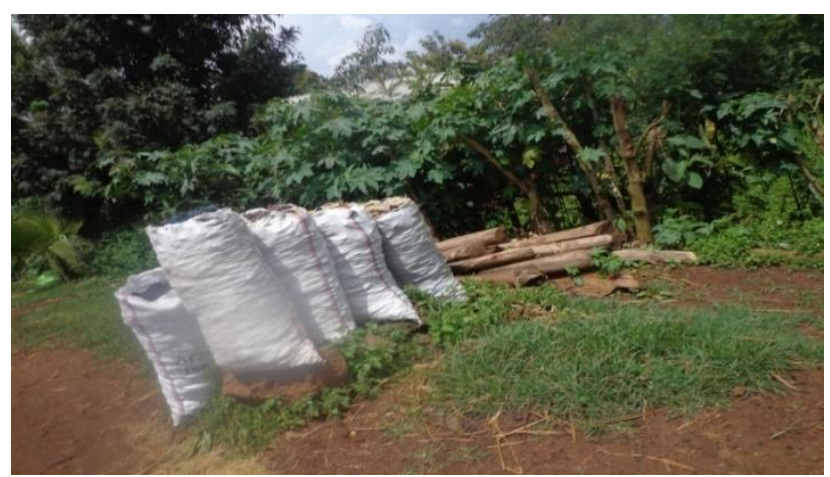

Figure 3 Soled charcoal for fuel in the study site

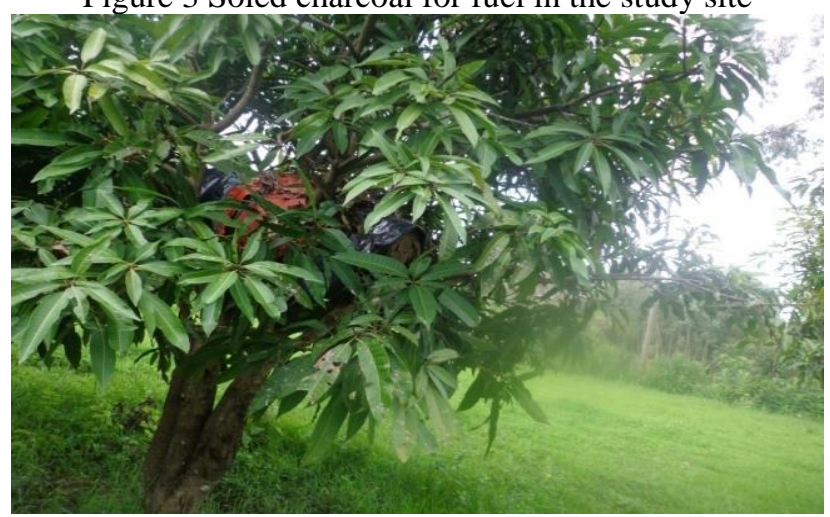

Figure 4 Mangifera indica serves hang beehives in the study site

Factors Influencing Fruit Tree Species Richness and Diversity in Home Garden

Age of the respondents was a socio-economic factor which influenced plant species diversity in home garden. It has been investigated that, older respondents had significantly higher $(\mathrm{P}<0.05)$ species richness and diversity than the younger ones. This implies that home garden agroforestry practices are developed through experiences from what the farmers observe and understood throughout their life (trial and error) and environmental conditions.

In the study area, lack of access to market and road, livestock are some commonly known factors affecting abundance of fruit tree species. Location of market place 
negatively or positively affected the farmers in growing woody species in home garden (Zemede Asfaw, 2001). Accordingly, villages with better access to the local market and main road showed a difference fruit tree species abundance compared to villages those far from market place and main road and also livestock, like apes and monkey affect fruit ripening and production.

Wealth status was another factor that influences woody species diversity of home garden agro-forestry. Across the study sites, rich households own significantly larger home gardens than medium and poor households. This indicates plant species cultivated in individual home gardens did vary among wealth categories. Several studies have reported the influence of wealth on the tree density and tree species richness on farmlands (Tesfaye et al.,2010).

Land availability is an important factor that determines the development of each component of home gardens. The average size of home garden at the study site was 0.43 ha per household, ranging from a minimum of 0.03 ha to a maximum of 1 ha. In the present study, mean home garden size increased as the total farm size increases thus increased woody species richness and diversity. A positive relationship between garden size and species richness has been documented by many workers, e.g. MoFED (2007) in Southern Ethiopia, Das and Das (2005) in India, and Sunwar (2003) in Nepal.

\section{Conclusions}

The study showed different species diversity status among the three considered wealth category (Poor, Medium, and Rich) within the study sites. A total of 18 fruit tree species represented by 9-genera and 7-families were recorded in home garden agro-forestry within the three wealth status (poor, medium, and rich) of the selected respondents commonly. The highest Shannon diversity index was recorded in rich and the lowest was in poor class category. The highest species evenness was recorded in rich wealth category, and there was no significant difference $(\mathrm{P}>0.05)$ among rich and medium wealth categories for species richness. The study also revealed that age, land hold size/home garden size, education status are the reason for species diversity in addition to the wealth status in the study area. Almost all $(100 \%)$ of the sampled households harvest and use at least four types of home garden products for various purposes.

\section{Acknowledgements}

We are grateful to thank the development agents (DAs) of the study sites who assisted us in facilitating the village level data collection by devoting their precious time. Our special thanks go to key informants and farm households in each peasant associations (PAs) for their immense contribution in the data collection processes.

\section{References}

CSA. 2008. Area and Production of Major Crops. Agricultural Sample Enumeration Survey. Addis Ababa, Ethiopia.

Das T, Das A. 2005. Inventorying Plant Biodiversity in Homegardens: A Case Study in Barak Valley, Assam, North East India. Current Science 89(1): 155-163.
Djurfeldt G, Aryeetey E, Isinika C. 2011. African smallholder's food crops markets and policy. CPI Antony Rowe. ed. United Kingdom.

Fentahun M. 2008. Fruit tree species in the wild and in home garden agro forestry: species composition, diversity and utilization in western Amhara, region Ethiopia. BOUK, Department for Forest and Soil Sciences, Vienna.

Fernandes EC. 2003. Definition of Homegardens. Online: http://www.css.cornell.edu/ecf3 web/ new/AF/home garden 01.htm/( accessed on 15.06. 2015).

Joosten F. 2007. Development Strategy for the export-oriented horticulture in Ethiopia.Wageningen, Netherlands.

Kehlenbeck K, Maass BL. 2004. Crop diversity and classification of home gardens in Central Sulawesi, Indonesia. Agroforest. Systeme 63(1): 53-62.

Kumar BM, Nair PKR .2006. Tropical Homegardens: A timetested Example of Sustainable Agroforestry. Environmental Experts S. L.

Magurran A. 2004. Measuring biological diversity. Blackwell Publishing Company, Malden.

Mendez VE. 2000. An assessment of tropical homegardens as examples of local sustainable agroforestry systems. In: Gliessman, S.R.(ed.) Agroecosystem sustainability: Developing practical strategies. CRC press: Boca Raton FL, USA. pp 51-66.

Mendez VE, Lok R, Somarriba E. 2001. interdisciplinary analysis of home gardening carague: microzonation, plant use and socioeconomic importance.Ageroforestsystem.51:85-96.

MoFED .2007. Ethiopia building on progress: a plan for accelerated and sustained development to end poverty Addis Ababa: Ministry of Finance and Economy Development. Annual progress report.

Salam MA, Noguchi T, koike M. 2000. understanding why farmers plant tree in the homestead ageroforestery in Bangladesh. Agero forest system.50:77-93.

Shannon CE, Wiener W.1949. The mathematical theory of communication. The University of Illinois press.

Sunwar S. 2003. Home gardens in western Nepal: Opportunities and challenges for on farm management of agro biodiversity. MSc thesis. Swedish Biodiversity Centre. No. 29.

Tefera M, Mirutse G, Ensermu K. 2015. Ethnobotanical study of homegarden plants in Sebeta-Awas District of the Oromia Region of Ethiopia to assess use, species diversity and management practices. Journal of Ethnobiology and Ethnomedicine 2015, 11:64 doi:10.1186/s13002-015-0049-8.

Tesfaye A, Wiersum KF, Bongers F.2010. Spatial and temporal variation in crop diversity in agroforestry homegardens of southern Ethiopia. Agroforest Syst 78:309-322.

Tsegazeabe H, Haileselasie M, Mekonen T, G/hiwot G, Gebremichael E, Solomon A. 2012. Hiluf Agroforestry Practices and Biodiversity Management in Backyards in Hiwane, Hintalo Wejerat of Tigray, Northern Ethiopia. Asian Journal of Agricultural Sciences 4(2): 110-116, ISSN: 20413890.

Wezel A, Bender S. 2003. Plant species diversity of homegardens of Cuba and its significance for household food supply. Agroforest. Syst. 57(1): 39-49.

Withrow-robinson B, Hibbs DE. 2005. Testing an ecologically based classification tool on fruit-based ageroforestery in northen Thailand. Agero-forestery system 65: 123- 135.

Wojtkowski PA. 1993. Toward an understanding of tropical homegardens. Agrofororesty systems 24: 215-222.

Zeberga S. 2010. Thesis on the production and quality evaluation of spray dried fruit production, Addis Ababa University, department of chemical engineering.

Zemede A. 2001. Origin and evolution of rural home gardens in Ethiopia. In: Friis, I.; Ryding, O. (eds.): Biodiversity research in the horn of Africa region. 